\title{
Pulmonary Perfusion and Ventilation during Cardiopulmonary Bypass Are Not Associated with Improved Postoperative Outcomes after Cardiac Surgery
}

\author{
Yiliam F. Rodriguez-Blanco', Angela Gologorsky ${ }^{2}$, Tomas Antonio Salerno ${ }^{3}$, Kaming Lo ${ }^{4}$ \\ and Edward Gologorsky ${ }^{5 *}$
}

\begin{abstract}
${ }^{1}$ Anesthesiology, University of Miami Miller School of Medicine, Miami, FL, USA, ${ }^{2}$ Private Practice, Anesthesiology, Miami, FL, USA, ${ }^{3}$ Cardiovascular Surgery, University of Miami Miller School of Medicine, Miami, FL, USA, ${ }^{4}$ Division of Biostatistics, Department of Public Health Sciences, University of Miami, Miami, FL, USA, ${ }^{5}$ Anesthesiology, Allegheny General Hospital, Pittsburgh, PA, USA
\end{abstract}

OPEN ACCESS

Edited by:

Massimo Bonacchi,

University of Florence, Italy

Reviewed by:

Pradeep Narayan,

NH RN Tagore Hospital, India

Michael Hofmann,

University of Zurich, Switzerland

*Correspondence:

Edward Gologorsky doctorsg@bellsouth.net

Specialty section:

This article was submitted

to Heart Surgery,

a section of the journal

Frontiers in Cardiovascular Medicine

Received: 07 October 2016 Accepted: 17 November 2016 Published: 28 November 2016

Citation:

Rodriguez-Blanco YF, Gologorsky A, Salerno TA, Lo K and Gologorsky E (2016) Pulmonary Perfusion and Ventilation during Cardiopulmonary

Bypass Are Not Associated with Improved Postoperative Outcomes after Cardiac Surgery. Front. Cardiovasc. Med. 3:47. doi: 10.3389/fcvm.2016.00047
Objectives: Clinical trials of either pulmonary perfusion or ventilation during cardiopulmonary bypass (CBP) are equivocal. We hypothesized that to achieve significant improvement in outcomes both interventions had to be concurrent.

Design: Retrospective case-control study.

Settings: Major academic tertiary referral medical center.

Participants: Two hundred seventy-four consecutive patients who underwent open heart surgery with CBP 2009-2013.

Interventions: The outcomes of 86 patients who received pulmonary perfusion and ventilation during CBP were retrospectively compared to the control group of 188 patients.

Measurements and main results: Respiratory complications rates were similar in both groups (33.7 vs. 33.5\%), as were the rates of postoperative pneumonia (4.7 vs. $4.3 \%$ ), pleural effusions (13.9 vs. 12.2\%), and re-intubations (9.3 vs. 9.1\%). Rates of adverse postoperative cardiac events including ventricular tachycardia (9.3 vs. $8.5 \%$ ) and atrial fibrillation (33.7 vs. $28.2 \%$ ) were equivalent in both groups. Incidence of sepsis (8.1 vs. $5.3 \%)$, postoperative stroke (2.3 vs. $2.1 \%$ ), acute kidney injury (2.3 vs. $3.7 \%$ ), and renal failure (5.8 vs. $3.7 \%$ ) was likewise comparable. Despite similar transfusion requirements, coagulopathy ( 12.8 vs. $5.3 \%, p=0.031$ ) and the need for mediastinal re-exploration (17.4 vs. $9.6 \%, p=0.0633$ ) were observed more frequently in the pulmonary perfusion and ventilation group, but the difference did not reach the statistical significance. Intensive care unit (ICU) and hospital stays, and the ICU readmission rates (7.0 vs. 8.0\%) were similar in both groups.

Conclusion: Simultaneous pulmonary perfusion and ventilation during CBP were not associated with improved clinical outcomes.

Keywords: cardiopulmonary bypass, postoperative complications, pulmonary perfusion, pulmonary ventilation, cardiac surgery outcome 


\section{INTRODUCTION}

Pulmonary dysfunction after open heart surgery is multifactorial. The relative contributions of various pathophysiologic factors remain obscure despite enormous experimental and clinical efforts (1-3). Cessation of alveolar ventilation and perfusion engendered in traditional technique of cardiopulmonary bypass ( $\mathrm{CPB}$ ) are thought to potentiate the effects of systemic inflammatory reaction associated with $\mathrm{CPB}$ and to contribute to postoperative pulmonary dysfunction. However, despite initial enthusiasm, attempts to mitigate iatrogenic atelectasis and alveolar ischemia had very limited impact on postoperative pulmonary dysfunction (4-7). We have argued in the past (8) that the disappointing inconsistency of these clinical trials stemmed from their focus on either pulmonary perfusion or ventilation but never on both simultaneously; we had proposed that binary interventions of either ventilation of ischemic alveoli or perfusion of atelectatic lungs were of unlikely benefit, and that to achieve favorable outcomes both interventions had to be concurrent; lungs had to be both perfused and ventilated during CPB (9). Therefore, we have studied the effects of simultaneous pulmonary perfusion and ventilation during $\mathrm{CPB}$ in comparison to traditional management of $\mathrm{CPB}$. We hypothesized that the pulmonary perfusion and ventilation was a safe technique that had the potential to reduce the incidence and severity of postoperative pulmonary dysfunction in patients undergoing open heart surgery.

\section{MATERIALS AND METHODS}

Following Institutional Review Board (IRB) approval, the medical records of 274 consecutive patients who underwent a cardiac valve procedure at Jackson Memorial Hospital/University of Miami between January 1, 2009 and December 30, 2013 were reviewed. No specific criteria were implemented other than cardiac surgery requiring CBP during the designated time frame. All data were anonymized before analysis. The informed consent for this retrospective study was waived.

\section{Data Collection}

All perioperative data were obtained from the electronic medical records. The collected data included multiple descriptors of patients' demographics, comorbidities, details of intraoperative course, perioperative transfusion requirements, duration of the intensive care unit (ICU) and hospital stays, and perioperative mortality and morbidity events. Postoperative pulmonary complications, re-intubation rates, need for postoperative re-exploration and transfusion, and adverse neurologic and renal events were all included in the analysis.

\section{Outcomes}

The outcomes of 86 patients who received pulmonary perfusion and ventilation during $\mathrm{CPB}$ (cohort of interest) were retrospectively compared to the outcomes of control group of 188 patients who had undergone conventional $\mathrm{CPB}$ management without pulmonary perfusion and ventilation.
The primary outcomes included the in-hospital morbidity and mortality rates. Secondary outcome measures included various postoperative complications including cardiac, pulmonary, neurologic and renal compromise, sepsis, duration of postoperative mechanical ventilator support in the ICU, length of ICU and hospital stays, and need for re-exploration and transfusion requirements.

\section{Intraoperative Management of Cardiopulmonary Bypass}

As a matter of surgical preference, in all patients, every attempt was made to avoid or to minimize the duration of cardioplegic arrest utilizing the "beating heart technique" $(10,11)$. While the systemic circulation was supported by $\mathrm{CPB}$, the unloaded ("empty") beating heart was continuously perfused (both in antegrade and retrograde fashion) with warm oxygenated blood. In certain circumstances, such as a difficult valve exposure, an excessively bloody field, or a perceived increased risk of embolization, cardioplegic arrest was induced. All the decisions regarding the administration of hyperkalemic cardioplegia and the duration of cardioplegic arrest were made by the surgeon based on the technical aspects of the surgery.

In the control group, pulmonary ventilation was suspended for the duration of the CPB, and no attempt was made to perfuse the pulmonary artery. In the cohort of interest, the following technique was used: pulmonary ventilation was maintained with inspired oxygen fraction $\left(\mathrm{FiO}_{2}\right)$ of 0.5 , tidal volumes of 4-6 $\mathrm{ml} / \mathrm{kg}$ of ideal weight, at a rate of 5 breaths $/ \mathrm{min}$, and endexpiratory pressure (PEEP) of $5 \mathrm{mmH}_{2} \mathrm{O}$. The pulmonary artery was perfused via a 3-mm diameter perfusion cannula attached to the aortic cannula. In this setup, pulmonary artery perfusion depended on the $\mathrm{CPB}$ flow and pressure, tubing length and resistance, and blood viscosity. At systemic flows of $2.41 / \mathrm{min} / \mathrm{m}^{2}$ and mean arterial pressures of $60 \mathrm{mmHg}$, Doppler-measured average pulmonary arterial flows ranged between 400 and $500 \mathrm{ml} / \mathrm{min}$. Presence of the alveolar perfusion was confirmed by steady values of end-tidal $\mathrm{CO}_{2}$ on continuous capnography (12). The decision to utilize the pulmonary perfusion and ventilation during $\mathrm{CPB}$ was exclusively the surgeon's.

\section{Statistical Analysis}

Descriptive statistics were used to describe all variables of interest within each of the comparison groups (lung perfusion/ventilation group vs. conventional technique group). Mean values and SDs were calculated for continuous variables that approximately follow the normal distribution and Student's $t$-tests were then used to compare the groups. Median values and interquartile ranges (IQR) were calculated for variables that were highly skewed and Wilcoxon's rank-sum tests were then used for comparison between the groups. Frequencies and proportions were used to analyze categorical variables. Chisquare tests or Fisher's exact tests were then used depending on the expected cell counts, to compare difference in proportions between the groups and to examine the overall trends. Due to the amount of comparisons performed, a Bonferroni adjusted type I error rate of 0.00091 was assumed for significance. All 
analyses were performed using SAS 9.4 (SAS Institute, Cary, NC, USA).

\section{RESULTS}

Preoperative demographics and clinical data are summarized in Table 1. Baseline demographics were similar between the groups. Of the 86 patients who received pulmonary perfusion and ventilation during $\mathrm{CPB}$, most were male (59.3\%) with a mean age of 58 years and a median left ventricular ejection fraction (EF) of 55\%. Comparably, of 188 patients in the control group, most were male (53.2\%), with a mean age of 57 and EF of $55 \%$. The most common comorbidities in both groups included hypertension (67.4 vs. $78.7 \%$ ), dyslipidemia (34.9 vs. $39.3 \%$ ), smoking (35 vs. $30 \%$ ), diabetes (30 vs. $27 \%$ ), chronic lung disease ( 22 vs. $19 \%$ ), and renal disease (19 vs. $10 \%)$. Even though the patients in the cohort of interest had higher incidence of a prior cerebrovascular event (19.7 vs. $10.1 \%)$, coronary artery disease (12.8 vs. $5.3 \%)$, prior coronary artery bypass grafting (CABG) (4.7 vs. $2.1 \%)$, prior valve surgery (17.4 vs. $7.9 \%)$, and preoperative ICU admissions (36.1 vs. 20.7\%), the difference was not statistically significant when Bonferroni correction to the $p$ values was applied. Patients in both groups had comparable rates of intubation and mechanical ventilation immediately prior to the surgery (3.5 vs. $5.3 \%)$.

Table 2 specifies the types of surgical procedures and summarizes the intraoperative data. In both groups, single valve surgery was the most common $(77.9 \%$ in the cohort of interest vs. $80.9 \%$ in the control group); rates of multiple valves surgery (10.5 vs. $7.5 \%)$ and of combined valve and CABG procedures (11.6 vs. $11.7 \%)$ were similar in both groups $(p=0.703)$. Transfusion rates (calculated as fraction of patients requiring at least $1 \mathrm{U}$ of autologous blood, \%) (94.2 vs. 95.7\%) and the average duration of surgery (time from the surgical incision to the end of surgery) were equal in both groups (4.5 vs. $4.7 \mathrm{~h}$ ).

Patients who had pulmonary perfusion and ventilation during CPB had significantly shorter CPB times (median 88 vs. 119 min, $p<0.0001)$ and higher rates of extubation in the OR (37.2 vs. $13.8 \%, p<0001)$.

Table 3 summarizes some postoperative events. Overall, patients in both groups had similar transfusion requirements (calculated as the fraction of patients requiring at least $1 \mathrm{U}$ of autologous blood, \%) (60.5 vs. 50.5\%, $p=0.126)$, duration of ICU ( 5 vs. 5 days) and hospital stays (9.3 vs. 9.5 days), and the ICU readmission rates ( 7.0 vs. $8.0 \%$ ).

Postoperative complications are tabulated in Table 4. Overall respiratory complications rates were similar in both groups (33.7 vs. $33.5 \%)$, as were the rates of postoperative pneumonia (4.7 vs. $4.3 \%$ ), pleural effusions (13.9 vs. $12.2 \%$ ), and re-intubations due to deterioration of pulmonary function (9.3 vs. $9.1 \%$ ). Rates of adverse postoperative cardiac events, such as ventricular tachycardia ( 9.3 vs. $8.5 \%$ ), atrial fibrillation (33.7 vs. $28.2 \%$ ), and cardiac arrest (11.6 vs. $10.6 \%)$, were equivalent in both groups. Incidence of sepsis ( 8.1 vs. $5.3 \%)$, new postoperative stroke $(2.3$ vs. $2.1 \%$ ), acute kidney injury (2.3 vs. $3.7 \%$ ), and renal failure (5.8 vs. $3.7 \%$ ) were similar in both groups.

TABLE 1 | Demographic data.

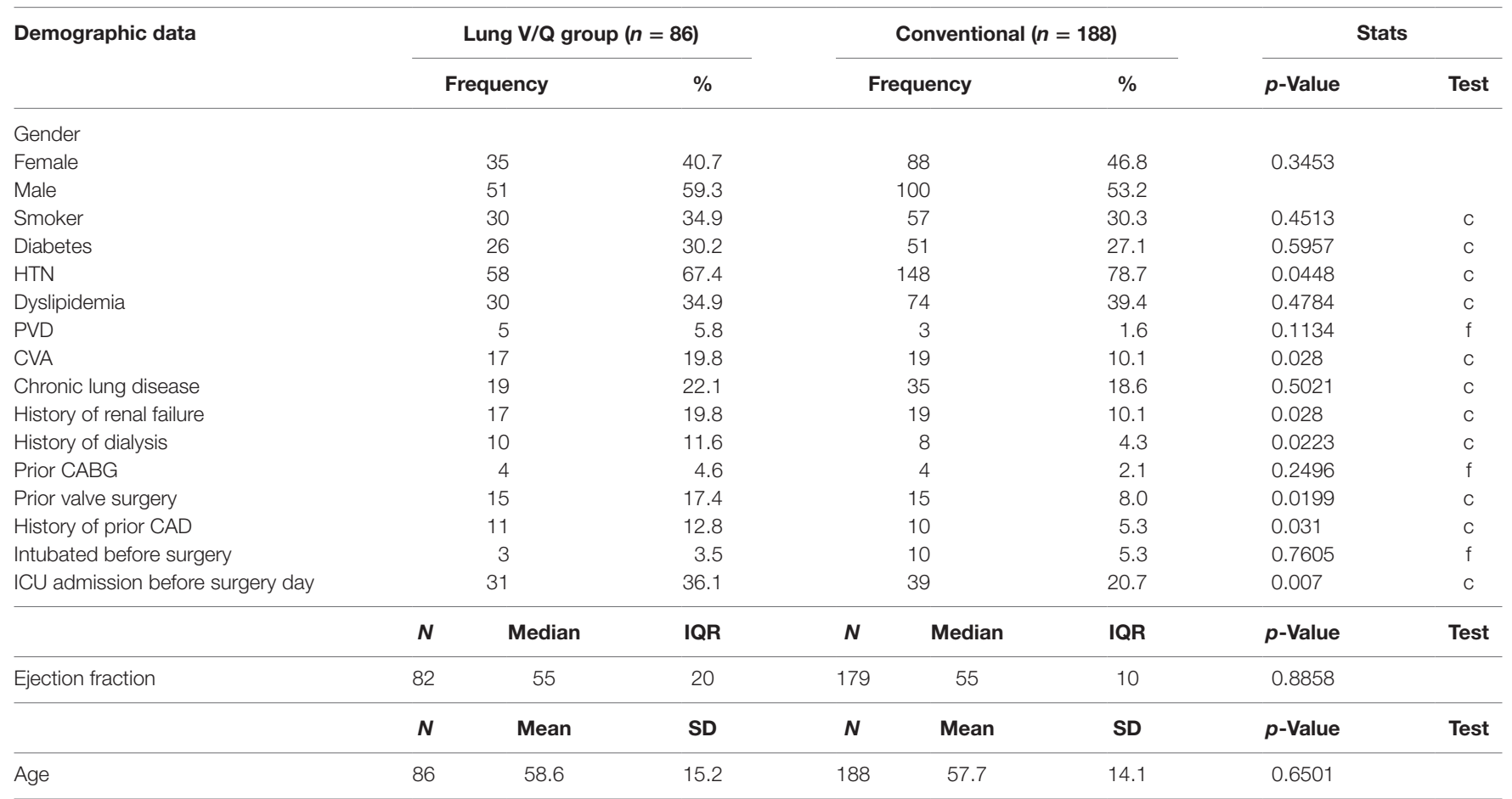

OR, operating room; HTN, hypertension; CVA, cerebrovascular accident; PVD, peripheral vascular disease; CAD, coronary artery disease; CABG, coronary artery bypass graft; ICU, intensive care unit; $V / Q$, pulmonary ventilation and perfusion.

Test: c, chi-square test; $f$, Fischer's exact test, $p$-value (adjusted alpha 0.0009). 
TABLE 2 | Intraoperative data.

\begin{tabular}{|c|c|c|c|c|c|}
\hline \multirow[t]{2}{*}{ Intraoperative data } & \multicolumn{2}{|c|}{ Lung V/Q group $(n=86)$} & \multicolumn{2}{|c|}{ Conventional $(n=188)$} & \multirow{2}{*}{$\begin{array}{c}\text { Stats } \\
p \text {-Value }\end{array}$} \\
\hline & Frequency & $\%$ & Frequency & $\%$ & \\
\hline Scheduled procedure & & & & & 0.703 \\
\hline Single valve & 67 & 77.9 & 152 & 80.8 & \\
\hline Double/triple valve & 9 & 10.5 & 14 & 7.4 & \\
\hline CABG plus valve & 10 & 11.6 & 22 & 11.7 & \\
\hline Intra-op blood products & 81 & 94.2 & 180 & 95.7 & $0.5538^{\mathrm{a}}$ \\
\hline \multirow[t]{2}{*}{ Extubation in the OR } & 32 & 37.2 & 26 & 13.8 & $<0.0001$ \\
\hline & Median & IQR & Median & IQR & $p$-Value \\
\hline CPB time, min & 88 & 41 & 119 & 75 & $<0.0001$ \\
\hline Time from incision to end of surgery, $\mathrm{h}$ & 4.5 & 1.9 & 4.725 & 2.5 & 0.0515 \\
\hline Time from end of surgery to out of OR, min & 25 & 22 & 25 & 20 & 0.3748 \\
\hline
\end{tabular}

OR, operating room; CABG, coronary artery bypass graft; V/Q, pulmonary ventilation and perfusion; CPB, cardiopulmonary bypass; min, minutes.

p-Value (adjusted alpha 0.0009). All associations involving categorical variables were examined using chi-square tests or Fisher exact tests ( ${ }^{2}$ ).

TABLE 3 | Postoperative course.

\begin{tabular}{|c|c|c|c|c|c|}
\hline Postoperative course & \multicolumn{2}{|c|}{ Pulmonary V/Q group $(n=86)$} & \multicolumn{2}{|c|}{ Conventional $(n=188)$} & $\begin{array}{c}\text { Stats } \\
p \text {-Value }\end{array}$ \\
\hline ICU stay, days & 5 & 5 & 5 & 5 & 0.6742 \\
\hline Postoperative hospital stay, days & Frequency & $\%$ & Frequency & $\%$ & $p$-Value \\
\hline Postoperative blood products transfusion & 52 & 60.5 & 95 & 50.5 & 0.126 \\
\hline
\end{tabular}

ICU, intensive care unit; $V / Q$, ventilation and perfusion.

p-Value (adjusted alpha 0.0009). All associations involving categorical variables were examined using Chi-square tests or Fisher exact tests.

TABLE 4 | Postoperative morbidity and mortality.

\begin{tabular}{|c|c|c|c|c|c|c|}
\hline Morbidity and mortality events & \multicolumn{2}{|c|}{ Lung V/Q group $(n=86)$} & \multicolumn{2}{|c|}{ Conventional $(n=188)$} & \multicolumn{2}{|c|}{ Stats } \\
\hline Respiratory & 29 & 33.7 & 63 & 33.5 & 0.9727 & c \\
\hline Pneumothorax & 4 & 4.6 & 13 & 6.9 & 0.471 & c \\
\hline Pleural effusion & 12 & 13.9 & 23 & 12.2 & 0.6923 & c \\
\hline Pneumonia & 4 & 4.6 & 8 & 4.3 & 1 & $f$ \\
\hline Stroke & 2 & 2.3 & 4 & 2.1 & 1 & $f$ \\
\hline AKI & 2 & 2.3 & 7 & 3.7 & 0.7244 & $f$ \\
\hline ARF & 5 & 5.8 & 7 & 3.7 & 0.526 & $f$ \\
\hline Cardiac arrest & 10 & 11.6 & 20 & 10.6 & 0.8077 & c \\
\hline Coagulopathy & 11 & 12.8 & 10 & 5.3 & 0.031 & c \\
\hline Cardiac tamponade & 2 & 2.3 & 9 & 4.8 & 0.5112 & $f$ \\
\hline
\end{tabular}

$V / Q$, ventilation and perfusion; $A K I$, acute kidney injury; $A R F$, acute renal failure.

Test: c, chi-square test; $f$, Fischer's exact test.

Coagulopathy ( 12.8 vs. $5.3 \%, p=0.031)$ and the need for mediastinal re-exploration ( 17.4 vs. $9.6 \%, p=0.0633)$ were observed more frequently in pulmonary perfusion and ventilation group, but the difference did not reach the statistical significance.
Table 5 lists the mortality events for both groups. Cardiac failure was the leading cause of mortality in patients after pulmonary perfusion and ventilation during $\mathrm{CPB}$ (8 out of 14 patients). Multisystem organ failure [defined as systemic inflammatory 
TABLE 5 | Mortality events.

\begin{tabular}{|c|c|c|c|}
\hline \multicolumn{2}{|c|}{ Pulmonary perfusion/ventilation group } & \multicolumn{2}{|l|}{ Conventional technique } \\
\hline Procedure & Events & Procedure & Events \\
\hline MV replacement (endocarditis) & $\begin{array}{l}\text { Septic shock and multisystem organ } \\
\text { failure }\end{array}$ & MV and TV repair + AVR & Septic shock and multisystem organ failure \\
\hline AVR & $\begin{array}{l}\text { Cardiogenic shock due to } \\
\text { postoperative Ml }\end{array}$ & MV replacement & $\begin{array}{l}\text { Sternal wound dehiscence, mediastinitis, sepsis, } \\
\text { multisystem organ failure }\end{array}$ \\
\hline $\begin{array}{l}\text { Redo MV replacement } \\
\text { (preoperative endocarditis) }\end{array}$ & MRSA bacteremia, septic shock, ARDS & Bentall procedure & Cardiac arrest \\
\hline $\begin{array}{l}\text { Emergency MV replacement due } \\
\text { to preoperative MI complicated } \\
\text { with PM rupture; ECMO }\end{array}$ & Cardiogenic shock & AVR & Septic shock and multisystem organ failure \\
\hline $\begin{array}{l}\text { Emergency AVR due to severe } \\
\text { acute AR and pulmonary edema } \\
\text { after attempted valvuloplasty }\end{array}$ & Cardiogenic shock & AVR CABGx2 & $\begin{array}{l}\text { Severe postoperative respiratory failure required } \\
\text { ECMO }\end{array}$ \\
\hline MV replacement & $\begin{array}{l}\text { Severe paravalvular leak, complicated } \\
\text { by ARDS }\end{array}$ & AVR & $\begin{array}{l}\text { Post-op cardiogenic shock; SIRS, multisystem } \\
\text { organ failure }\end{array}$ \\
\hline MV repair & $\begin{array}{l}\text { Exacerbation of } \mathrm{CHF} \text { and } \mathrm{ARF} \text { due } \\
\text { to rejection of transplanted kidney, } \\
\text { cardiogenic shock }\end{array}$ & AVR CABGX1 & Severe postoperative respiratory failure \\
\hline AVR & $\begin{array}{l}\text { Massive stroke with irreversible brain } \\
\text { injury }\end{array}$ & $\begin{array}{l}\text { Emergency MV replacement } \\
\text { due to endocarditis and stroke }\end{array}$ & $\begin{array}{l}\text { Severe postoperative respiratory failure requiring } \\
\text { ECMO support, septic shock, multisystem organ } \\
\text { failure }\end{array}$ \\
\hline $\begin{array}{l}\text { Emergency AVR CABGx2 due } \\
\text { to left main coronary occlusion } \\
\text { and AS }\end{array}$ & $\begin{array}{l}\text { Cardiogenic shock, SIRS complicated } \\
\text { with multisystem organ failure }\end{array}$ & AVR CABGX1 & Refractory cardiogenic shock \\
\hline $\begin{array}{l}\text { Emergency MV replacement } \\
\text { CABGX1 due to } \mathrm{MI} \text { and PM } \\
\text { rupture }\end{array}$ & $\begin{array}{l}\text { Cardiogenic shock; SIRS complicated } \\
\text { with multisystem organ failure }\end{array}$ & $\begin{array}{l}\text { AVR, MV replacement due to } \\
\text { endocarditis following major } \\
\text { burn injury }\end{array}$ & ARDS, SIRS, multisystem organ failure \\
\hline MV replacement & Respiratory failure & AVR CABGX1 & $\begin{array}{l}\text { Developed delayed symptomatic lung infiltrates } \\
\text { requiring re-intubation; succumbed later to } \\
\text { refractory respiratory failure }\end{array}$ \\
\hline MV replacement & Cardiogenic shock & $\begin{array}{l}\text { MV replacement due to } \\
\text { endocarditis }\end{array}$ & Sepsis, multisystem organ failure \\
\hline $\begin{array}{l}\text { Emergency TV repair due to } \\
\text { endocarditis }\end{array}$ & $\begin{array}{l}\text { Postoperative septic shock complicated } \\
\text { with severe heart failure, required } \\
\text { postoperative ECMO support }\end{array}$ & Bentall procedure & $\begin{array}{l}\text { Postoperative sternal wound infection, sepsis, } \\
\text { multisystem organ failure }\end{array}$ \\
\hline $\begin{array}{l}\text { Redo }(\times 3) \text { MV replacement, TV } \\
\text { repair due to endocarditis }\end{array}$ & SIRS, multisystem organ failure & $\begin{array}{l}\text { AVR } \\
\text { AVR } \\
\text { AVR due to endocarditis }\end{array}$ & $\begin{array}{l}\text { Cardiogenic shock, unable to wean off CPB, } \\
\text { postoperative ECMO } \\
\text { Cardiac arrest in the ICU } \\
\text { Cardiogenic shock }\end{array}$ \\
\hline
\end{tabular}

MV, mitral valve; AVR, aortic valve replacement; TV, tricuspid valve; CABGx1, coronary artery bypass grafting, CABGx2, coronary artery bypass grafting, two vessels; one vessel; SIRS, systemic inflammatory response syndrome; MRSA, methicillin-resistant Staphylococcus aureus; ARDS, acute respiratory distress syndrome; CPB, cardiopulmonary bypass; ECMO, extracorporeal membrane oxygenation.

response syndrome (SIRS) with or without documented systemic infection] contributed to mortality in four patients, and respiratory failure (defined as persistent, severe, and refractory hypoxemia) was seen in three patients. In the control group, 8 out of 16 patients succumbed to septic complications and SIRS with multisystem organ failure, 8 to postoperative cardiac failure, and 4 to severe respiratory failure. Overall mortality rates, though higher in the cohort of interest, were not statistically different (16.3 vs. $8.5 \%, p=0.056$ ).

\section{DISCUSSION}

Our study failed to demonstrate clinically significant benefits of simultaneous pulmonary perfusion and ventilation during CPB. These findings are in contrast with Suzuki et al. (13), who reported a significantly shorter duration of postoperative mechanical ventilation and improved alveolar function in infants who were subjected to $30 \mathrm{ml} / \mathrm{kg} / \mathrm{min}$ pulmonary artery perfusion flows during $\mathrm{CPB}$ in the course of corrective surgery for 
congenital heart disease. Our study was considerably different: all patients were adults, "beating heart" technique rather than hypothermic hyperkalemic cardiac arrest was used whenever possible, and pulmonary perfusion flows were significantly lower (close to $500 \mathrm{ml} / \mathrm{min}$ ). Clinical studies in settings resembling our study are less sanguine. Selective continuous pulmonary artery perfusion flows of $7 \mathrm{ml} / \mathrm{kg} / \mathrm{min}$, comparable to those used in our study, in low-risk adult patients during on-bypass coronary revascularization resulted in no significant clinical benefits (14, 15) despite slightly improved pulmonary perfusion indices and decreased pulmonary tissue inflammatory cytokine production. Importantly, Kiessling et al. (5) reported an absence of clinical benefits despite small trends toward decreased pulmonary tissue-generated inflammatory markers in a study of intermittent selective pulmonary perfusion in high-risk pulmonary patients undergoing on-bypass coronary revascularization. Similar to our results, the latter study demonstrated a statistically insignificant unfavorable trend toward increased overall mortality and pulmonary morbidity. Animal studies of selective partial pulmonary perfusion during CPB reported inconclusive results as well (16), citing a low study size and possibly insufficient duration of the pulmonary artery perfusion.

Studies of alveolar ventilation during CPB suffer from a similar dichotomy between in vivo findings and clinical outcomes. In a pig model, Imura et al. (17) demonstrated preservation of transalveolar gas change and metabolic and histologic evidence of protective effects of low-frequency ventilation on histoarchitecture and function of alveolar membrane. However, these protective effects were not clinically evident (6), likely due to large data variability and insufficient study size. In an attempt to increase the power of these studies, a meta-analysis was performed of 16 clinical trials with a total enrollment of 814 patients (7). Various methods of ameliorating iatrogenic atelectasis during CPB included continuous positive alveolar pressure, lowfrequency ventilation, and vital capacity recruitment maneuvers. Irrespective of the method, the clinical effects were short lived and did not impact the outcomes.

Outcome studies of fully maintained pulmonary perfusion and ventilation during bypass as in the Drew-Anderson technique (bilateral extracorporeal circulation without a membrane oxygenator, using patients' lungs as a natural oxygenator) are not without controversy as well. Richter et al. (18) reported a significant decrease in inflammatory cytokines with clinically significant improvements in hemostasis, postoperative pulmonary function, and shorter times of mechanical ventilator support. However, a recent animal study of the same technique (19) did not find any change in inflammatory cytokines production by pulmonary tissue despite electron microscopy evidence of the mitigating effects of pulmonary perfusion and ventilation on polymorphonuclear leukocytes infiltration, interstitial edema formation, and histoarchitecture disruption associated with conventional CPB.

Translating theoretical concepts into clinical outcomes remains an ever-elusive goal. Even such well-established concepts as the deleterious effects of inflammatory cytokines still await their correlation with specific clinical end-points. While Siepe et al. (20) attributed the protective effects of pulmonary perfusion during
$\mathrm{CPB}$ to the decreased pulmonary tissue expression and blood concentration of inflammatory cytokines, such as IL-6, IL-8, IL-10, and TNF- $\alpha$, and others $(5,15,19)$ could not reproduce these effects. Likewise, despite avoidance of $\mathrm{CPB}$, pulmonary atelectasis and activation of inflammatory cascades associated with pulmonary ischemia-reperfusion injury, off-bypass technique of coronary revascularization offers only a modest clinical impact on pulmonary outcomes in patients with severe pulmonary disease (21-23).

Absence of proof is not a proof of absence. Nevertheless, an apparent lack of clinically significant benefits of pulmonary perfusion and ventilation during $\mathrm{CPB}$ begs for an explanation. We could speculate that in a milieu of multiple concurrent operational pathophysiologic mechanisms, mitigating some of the variables may not translate into an observable clinical effect (24). Patients in both groups had comparable incidences of non-modifiable risks of postoperative pulmonary dysfunction and ventilator dependency such as advanced age, reduced preoperative pulmonary function, smoking, renal insufficiency, recent myocardial infarction, and reduced left ventricular function. Untoward effects of CBP may be confounded by altered pulmonary mechanics due to sternothomy, internal mammary artery harvest, pleural entry, and phrenic nerve injury (3, 23, 25-27). In the present study, the majority of the patients in both groups were exposed to blood products perioperatively, an additional and a significant confounding factor associated with a possibility of a delayed lung injury (28). There is also a growing appreciation for the importance of factors not included in our study, such as right ventricular (RV) function and mode of perioperative ventilation. Even though RV performance is not included yet in STS risk score calculation, it had emerged as an important independent factor for perioperative morbidity and mortality in some critically ill populations $(29,30)$. Similarly, the impact of ventilation strategies on RV pulmonary blood flow functionality and on pulmonary and overall outcomes is increasingly understood and appreciated (31-35). Additionally, the institutional structure, and expertise and experience of individual surgeons, anesthesiologists, and intensivists $(23,36,37)$ may be important, but difficult to quantify. While the institutional bias was eliminated in our study, effects of interprovider variability could not be reliably ruled out.

Our study suffers from multiple limitations. It is retrospective and could not be randomized, and strong interprovider variability is likely. A small sample size may have prevented the detection of some significant differences. Some factors, such as $\mathrm{RV}$ function and rationale for various decisions and management preferences, were not recorded and their contribution to postoperative outcomes remains unknown. A retrospective differential diagnosis to establish the relative contributions of cardiac and pulmonary pathology in mortality events was difficult in many cases. Nevertheless, we believe the validity of our study, since the largely negative results were obtained despite shorter $\mathrm{CPB}$ and cross-clamp times and higher rates of extubation in the OR in the cohort of interest.

In conclusion, our data failed to demonstrate any clinical benefits of simultaneous pulmonary perfusion and ventilation during $\mathrm{CPB}$. It underscores the difficulty to translate attractive 
theoretical concepts tested in small in vivo studies into clinical practice. We believe that multiple confounders and outliers inherent in the care of heterogenous populations may account for our largely negative results. It is eminently possible that the described technique of simultaneous pulmonary perfusion and ventilation during CPB may prove of benefit in highly select groups of patients, such as elderly, those with significant preoperative pulmonary comorbidities, and those with advanced and symptomatic heart failure. As our database is expanded, we hope to be able to differentiate the outcomes of simultaneous pulmonary perfusion and ventilation during $\mathrm{CPB}$ according to the type and the severity of preoperative pulmonary comorbidity.

\section{REFERENCES}

1. Thell R, Hiesmayr M. Chapter 30. Pulmonary complications after cardiac surgery. In: Alston RP, Myles PS, Ranucci M, editors. Oxford Textbook of Cardiothoracic Anaesthesia. Oxford: Oxford University Press (2015). p. $339-45$.

2. Apostolakis EE, Koletsis EN, Baikoussis NG, Siminelakis SN, Papadopoulos GS. Strategies to prevent intraoperative lung injury during cardiopulmonary bypass. J Cardiothorac Surg (2010) 11(5):1. doi:10.1186/1749-8090-5-1

3. WeissmanC.Pulmonarycomplicationsaftercardiacsurgery.Semin Cardiothorac Vasc Anesth (2004) 8(3):185-211. doi:10.1177/108925320400800303

4. Al Jaaly E, Zakkar M, Fiorentino F, Angelini GD. Pulmonary protection strategies in cardiac surgery: are we making any progress? Oxid Med Cell Longev (2015) 2015:41623. doi:10.1155/2015/416235

5. Kiessling AH, Guo FW, Gökdemir Y, et al. The influence of selective pulmonary perfusion on the inflammatory response and clinical outcome of patients with chronic obstructive pulmonary disease undergoing cardiopulmonary bypass. Interact Cardiovasc Thorac Surg (2014) 18(6):732-9. doi:10.1093/ icvts/ivu062

6. Gagnon J, Laporta D, Béique F, Langlois Y, Morin JF. Clinical relevance of ventilation during cardiopulmonary bypass in the prevention of postoperative lung dysfunction. Perfusion (2010) 25(4):205-10. doi:10.1177/ 0267659110373839

7. Schreiber JU, Lance MD, Korte MD, Artmann T, Aleksic I, Kranke P. The effects of different lung-protective strategies in patients during cardiopulmonary bypass: a meta-analysis and semiquantitative review of randomized trials. J Cardiothorac Vasc Anesth (2012) 26:448-54. doi:10.1053/j.jvca. 2012.01.034

8. Macedo FI, Carvalho EM, Gologorsky E, Salerno TA. Lung ventilation/perfusion may reduce pulmonary injury during cardiopulmonary bypass. J Thorac Cardiovasc Surg (2010) 139(1):234-6. doi:10.1016/j.jtcvs.2009.08.062

9. Salerno TA, Macedo FI, Gologorsky E. Pulmonary ventilation should be matched with pulmonary perfusion during cardiopulmonary bypass. J Cardiothorac Vasc Anesth (2012) 26(5):e60. doi:10.1053/j.jvca.2012.04.014

10. Salerno TA, Panos AL, Tian G, Deslauriers R, Calcaterra D, Ricci M. Surgery for cardiac valves and aortic root without cardioplegic arrest ("beating heart"): experience with a new method of myocardial perfusion. J Card Surg (2007) 22(6):459-64. doi:10.1111/j.1540-8191.2007.00448.x

11. Ricci M, Macedo FI, Suarez MR, Brown M, Alba J, Salerno TA. Multiple valve surgery with beating heart technique. Ann Thorac Surg (2009) 87(2):527-31. doi:10.1016/j.athoracsur.2008.10.030

12. Macedo FI, Gologorsky E, Costa AC, Pham SM, Salerno TA. Beating heart surgery with lung perfusion-ventilation during cardiopulmonary bypass: target organs perfusion without plegia. Semin Thorac Cardiovasc Surg (2012) 24(4):308-10. doi:10.1053/j.semtcvs.2012.08.002

13. Suzuki T, Fukuda T, Ito T, Inoue Y, Cho Y, Kashima I. Continuous pulmonary perfusion during cardiopulmonary bypass prevents lung injury in infants. Ann Thorac Surg (2000) 69:602-6. doi:10.1016/S0003-4975(99)01332-6

14. Santini F, Onorati F, Telesca M, Patelli F, Berton G, Franchi G, et al. Pulsatile pulmonary perfusion with oxygenated blood ameliorates pulmonary hemodynamic and respiratory indices in low-risk coronary artery bypass
Further investigations of the effects of this technique in critically ill patients are needed.

\section{AUTHOR CONTRIBUTIONS}

YR-B: design, data collection, drafting of the article, and approval of article. AG: concept development, drafting of the article, critical revisions, and approval of article. TS: concept development, critical revisions, and approval of article. KL: data analysis/interpretation, drafting of the article, critical revisions, and approval of article. EG: concept development, design, data analysis/interpretation, drafting of the article, critical revisions, and approval of article.

patients. Eur J Cardiothorac Surg (2011) 40(4):794-803. doi:10.1016/j.ejcts. 2011.01.065

15. Santini F, Onorati F, Telesca M, Menon T, Mazzi P, Berton G, et al. Selective pulmonary pulsatile perfusion with oxygenated blood during cardiopulmonary bypass attenuates lung tissue inflammation but does not affect circulating cytokine levels. Eur J Cardiothorac Surg (2012) 42(6):942-50. doi:10.1093/ ejcts/ezs199

16. Gabriel EA, Fagionato Locali R, Katsumi Matsuoka P, Santiago Almeida L, Guerreiro Silva I, Capelozzi VL, et al. Lung perfusion during cardiac surgery with cardiopulmonary bypass: is it necessary? Interact Cardiovasc Thorac Surg (2008) 7(6):1089-95. doi:10.1510/icvts.2008.184275

17. Imura H, Caputo M, Lim K, Ochi M, Suleiman MS, Shimizu K, et al. Pulmonary injury after cardiopulmonary bypass: beneficial effects of low-frequency mechanical ventilation. J Thorac Cardiovasc Surg (2009) 137(6):1530-7. doi:10.1016/j.jtcvs.2008.11.014

18. Richter JA, Meisner H, Tassani P, Barankay A, Dietrich W, Braun SL. Drew-Anderson technique attenuates systemic inflammatory response syndrome and improves respiratory function after coronary artery bypass grafting. Ann Thorac Surg (2000) 69(1):77-83. doi:10.1016/S0003-4975(99) 01131-5

19. Freitas CR, Malbouisson LM, Benicio A, Negri EM, Bini FM, Massoco CO, et al. Lung perfusion and ventilation during cardiopulmonary bypass reduces early structural damage to pulmonary parenchyma. Anesth Analg (2016) 122(4):943-52. doi:10.1213/ANE.0000000000001118

20. Siepe M, Goebel U, Mecklenburg A, Doenst T, Benk C, Stein P, et al. Pulsatile pulmonary perfusion during cardiopulmonary bypass reduces the pulmonary inflammatory response. Ann Thorac Surg (2008) 86:115-22. doi:10.1016/j. athoracsur.2008.03.062

21. Parissis H, Mbarushimana S, Ramesh BC, Parissis M, Lampridis S, Mhandu $\mathrm{P}$, et al. The impact of off-pump surgery in end-organ function: practical end-points. J Cardiothorac Surg (2015) 10(10):159. doi:10.1186/s13019-015$0362-2$

22. Kerendi F, Halkos ME, Puskas JD, Lattouf OM, Kilgo P, Guyton RA, et al. Impact of off-pump coronary artery bypass graft surgery on postoperative pulmonary complications in patients with chronic lung disease. Ann Thorac Surg (2011) 91(1):8-15. doi:10.1016/j.athoracsur.2010.08.003

23. Lachapelle $\mathrm{K}$. Invited commentary. Impact of off-pump coronary artery bypass graft surgery on postoperative pulmonary complications in patients with chronic lung disease. Ann Thorac Surg (2011) 91(1):15. doi:10.1016/j. athoracsur.2010.08.057

24. Ioannidis JPA. Why most published research findings are false. PLoS Med (2005) 2(8):e124. doi:10.1371/journal.pmed.0020124

25. Ji Q, Mei Y, Wang X, Feng J, Cai J, Ding W. Risk factors for pulmonary complications following cardiac surgery with cardiopulmonary bypass. Int J Med Sci (2013) 10(11):1578-83. doi:10.7150/ijms.6904

26. Reddy SL, Grayson AD, Griffiths EM, Pullan DM, Rashid A. A logistic risk model for prolonged ventilation after adult cardiac surgery. Ann Thorac Surg (2007) 84(2):528-36. doi:10.1016/j.athoracsur.2007.04.002

27. Cislaghi F, Condemi AM, Corona A. Predictors of prolonged mechanical ventilation in a cohort of 5123 cardiac surgical patients. Eur J Anaesthesiol (2009) 26(5):396-403. doi:10.1097/EJA.0b013e3283232c69 
28. Marik PE, Corwin HL. Acute lung injury following blood transfusion: expanding the definition. Crit Care Med (2008) 36(11):3080-4. doi:10.1097/ CCM.0b013e31818c3801

29. Cavalcante JL, Rijal S, Althouse AD, Delgado-Montero A, Katz WE, Schindler JT, et al. Right ventricular function and prognosis in patients with low-flow, low-gradient severe aortic stenosis. J Am Soc Echocardiogr (2016) 29(4): 325-33. doi:10.1016/j.echo.2015.12.001

30. Quader N, Lindman BR. Shifting the spotlight onto the forgotten ventricle: role of the right ventricle in low-flow, low-gradient aortic stenosis. J Am Soc Echocardiogr (2016) 29(4):334-6. doi:10.1016/j.echo.2016.02.006

31. Romagnoli S, Ricci Z. Lung protective ventilation in cardiac surgery. Heart Lung Vessel (2015) 7(1):5-6.

32. Neto AS, Simonis FD, Barbas CS, Biehl M, Determann RM, Elmer J, et al. Lung-protective ventilation with low tidal volumes and the occurrence of pulmonary complications in patients without acute respiratory distress syndrome: a systematic review and individual patient data analysis. Crit Care Med (2015) 43(10):2155-63. doi:10.1097/CCM.0000000000001189

33. Güldner A, Kiss T, Serpa Neto A, Hemmes SN, Canet J, Spieth PM, et al. Intraoperative protective mechanical ventilation for prevention of postoperative pulmonary complications: a comprehensive review of the role of tidal volume, positive end-expiratory pressure, and lung recruitment maneuvers. Anesthesiology (2015) 123(3):692-713. doi:10.1097/ALN.0000000000000754

34. Sutherasan Y, Vargas M, Pelosi P. Protective mechanical ventilation in the non-injured lung: review and meta-analysis. Crit Care (2014) 18(2):211. doi: $10.1186 /$ cc13778
35. Voelkel NF, Bogaard HJ, Gomez-Arroyo J. The need to recognize the pulmonary circulation and the right ventricle as an integrated functional unit: facts and hypotheses (2013 Grover Conference series). Pulm Circ (2015) 5(1):81-9. doi:10.1086/679702

36. Khandelwal N, Dale CR, Benkeser DC, Joffe AM, Yanez ND III, Treggiari MM. Variation in tracheal reintubations among patients undergoing cardiac surgery across Washington state hospitals. J Cardiothorac Vasc Anesth (2015) 29(3):551-9. doi:10.1053/j.jvca.2014.11.009

37. Glance LG, Kellermann AL, Hannan EL, Fleisher LA, Eaton MP, Dutton $\mathrm{RP}$, et al. The impact of anesthesiologists on coronary artery bypass graft surgery outcomes. Anesth Analg (2015) 120(3):526-33. doi:10.1213/ANE. 0000000000000522

Conflict of Interest Statement: The authors declare that the research was conducted in the absence of any commercial or financial relationships that could be construed as a potential conflict of interest.

Copyright (c) 2016 Rodriguez-Blanco, Gologorsky, Salerno, Lo and Gologorsky. This is an open-access article distributed under the terms of the Creative Commons Attribution License (CC BY). The use, distribution or reproduction in other forums is permitted, provided the original author(s) or licensor are credited and that the original publication in this journal is cited, in accordance with accepted academic practice. No use, distribution or reproduction is permitted which does not comply with these terms. 